in the peritoncal cavity. Intestines more or less congested. No general peritonitis. The portion constricted of a dark claret color. Not perforated. Its coats thickened and ecchymosed and slightly attached to the contiguous portion of intestine by bands of adhesion.

The trichina spiralis was found in the muscles, appearing as a series of white specks throughout. They were alive 48 hours after the death of the patient. None were found in the muscles of the lower extremities.

\section{BOSTON DISPENSARY.}

Remarks on the cases of Thoracic Disease occurring in the Men's Room during the month of January. By F. I. KNIGHT, M.D., one of the Physicians.

As usual at this season of the year, a large proportion of those seeking relief are suffering from some pulmonary affection. During the month, seventy-seven cases of bronchitis have presented themselves, some of them sub-acute and some chronic; a considerable number of the latter with marked signs of vesicular emphysema.

As there has been some difference of opinion as to the pitch of the respiratory murmur in cases of emphysema, particular attention was directed to this, and it was found to be invariably low, except in those regions of the chest where we might get the respiration higher in pitch than the inspiration in the healthy chest.

The treatment of the chronic cases has been somewhat novel and perhaps worthy of note.

Last winter Dr. J. W. Howe, then House Physician at Bellevue Hospital, New York City, conceived an idea that linseed oil, which he had seen used in broken winded horses, might be of service in the vesicular emphysema of men, and accordingly employed it, with considerable success. I was sufficiently impressed with its apparent effects to administer it this season in upwards of one hundred cases of chronic bronchitis, and the result has been certainly most satisfactory.

The proportion used has been as follows: R. Olei lini, syrupi simplicis, $\bar{a} \bar{a} \mathbf{3}$. ; olei menthæ pip., gt. ss. M. ter die.

One of the most noticeable effects seems to have been a diminution of the dyspnca, which usually accompanies long-standing cases of this nature.

Dr. Howe's trial of this remedy in this class of cases is the first, as far as I know, in this country. In German books on materia medica, this use of oleum lini is mentioned, but no particular efficacy seems to have been accorded it. I cannot say but that the peppermint in the above mixture may have had something to do with its effects, but that it has been of decided benefit to a large majority of those taking it there is no doubt. Of course we cannot expect any one drug or mixture to cure or relieve all cases of chronic bronchitis, but I have not seen any one, not even the iodide of potassium, which has given relief to so large a percentage of cases.

There.were thirty-eight new cases of phthisis. And what can we say of the treatment of them? The chief medicament, if so it can be called, has been the cod-liver oil, with such stimulants as they could obtain.

In the commencement of the season I put a considerable number of patients on the hypophosphite of lime alone, but as they evinced no improvement in a month's use of it, I did not feel at liberty to keep them longer on it exclusively, and so either substituted cod liver oil, or gare the two remedies together. I do not mean that they were administered in combination; the hypophosphite of lime was always prescribed just before meals, and the cod liver oil from one to two hours after.

I am aware that many of the preparations of the hypophosphites are bad, and it may have been on this account that the hypophosphite of lime did not seem to be of service in these cases, although every precaution was taken to obtain a good article. I would not by any means dissuade any one from the use of it, for I think I have seen good effects from it in private practice, though there it has been generally so combined with cod liver oil and stimulants, and such changes in hygienic conditions as the physician is likely to institute, that $I$ could judge only imperfectly.

One of the cases of phthisis is worthy of notice as showing how, by a change of habits, and by the employment of proper remedies, advanced disease may be arrestted even in this climate and in the winter season, and the patient recover a good degree of health and strength.

One day, intending to illustrate the normal difference on percussion at the summit of the two sides of the chest, I called up from among the patients, a fine healthy: looking young man of about 18, and on practising percussion found, to my surprise, purely tympanitic resonance at the summit of the right chest in front. On auscultation I found good cavernous respiration and whisper in the same place, with as good pectoriloquy, i. e., actual transmission of

VoL. I.-No. $14 \mathrm{~A}$ 
speech, not sound, as is often heard. Below on the same side were all the signs of solidification.

This young man told me that last fall he got "run down," and had a little cough; but having left off work, and taken medicine, what he knew not, he now felt well except that he was not so strong as formerly. He certainly appeared healthy. I found he still had a little cough. He was put upon cod liver oil, and enjoined not to go back to his work. He was, fortunately, able to lead an easy life through the kindness of his relations, and has continued to gain strength steadily. The physical signs remain the same, but there has been no evidence of any progress of the disease since the first day he was examined. If he progresses favorably the case will be reported at length, so there is no occasion for going farther into details at the present time.

The number of cardiac cases has been comparatively small, from the fact that organic disease of the heart does not generally cause sufficient disturbance to lead a person to apply for advice until it has advaniced, and from the fact that functional disorder of the heart occurs much more frequently in women than in men.

An interesting case of Graves's disease, of long standing, with no exophthalmos, has been already reported in the last number of the Journal. Among the cases of organic disease one of enlargement of the heart was interesting, as presenting the mitral direct or obstructive murmur. That is, the lesion on which the enlargement of the heart in this case depended, was mitral obstruction, and the murmur denoting this lesion is called the mitral direct murmur, because it occurs during the normal passage of blood from the left auricle to the left ventricle, just before the first sound, and ending abruptly with it. It is heard loudest near the apex of the heart.

This murmur is often passed over as a regurgitant, but a glance at our physiology will fix the direct just before, and the regurgitant with the first sound. This distinction is very easy to make, though at first sight it may not seem so. In this case the aortic second sound was weakened by the diminished supply of blood to the aorta, and the pulmonic second sound absolutely intensified as a consequence of the hypertrophy of the right ventricle.

In conclusion, it may be well to mention that we may have the mitral direct murmur without lesion of the mitral valve. For, as has been shown by Dr. Flint, " in some cases in which free aortic regurgitation exists, the left ventricle becoming filled before the auricles contract, the mitral curtains are floated out, and the valve closed when the mitral direct current takes place, and under these circumstances this murmur may be produced by the current first named, although no mitral lesions exist."

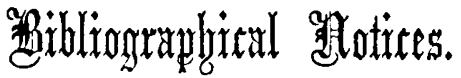

Dictionnaire Annuel des Progrès des Sciences et Institutions Médicales. Par M. Garnier. Quatrième Année. 1867. Paris: Baillière. 1868. Pp. 547.

Is an introductory chapter, Dr. Amedée Latour notices this French Retrospect, and compares it favorably with Canstatt, Ranking, Braithwaite and others. It is now in its fourth year. Dr. Latour touches briefly on the various subjects of professional interest which have given rise to debate during the year. Such are Tubercle, Infant Mortality, the Degeneration of Race, Animal Vaccination, Trephining, and Medical Responsibility. He advocates the establishment of a medical school of the hospitals of Paris.

The work of M. Garnier seems to have been carefully and consistently done. The book contains a general allusion to all novel points. We are pleased to see that we of the United States are not forgotten. No less than seven articles from the Boston Medical and Surgical Journal are noticed at some length, viz.: On Ununited Fracture ; on Trephining the Spine; on Perineal Section by the direct (Cox's) Method; on Esophagotomy ; on Cerebro-Spinal Meningitis; on the Hydrostatic Atomizer; and on Chorea.

Non-Antagonism of Belladonna and OpiUM.-Dr. John Hurley, in a lecture delivered at the Royal College of Physicians, London, reported in the Medical Times and Gazelte, concludes, as the result of experiments on the horse, the dog, and on man, that these medicines not only intensify, but very much prolong each other's effects, and this whether both are given at the same time or one is administered some time previous to the other. The only conclusion he could draw from his experiments was that belladonna decidedly increased the hypnotic effects of the opium, while opium greatly intensified not one or two only, but all the effects of belladonna. 